\title{
Formação de mudas de mamão em ambientes de cultivo protegido em diferentes substratos
}

Edilson Costa ${ }^{1}$; Viviane do Amaral Gomes Mesquita²; Paulo Ademar Martins Leal ${ }^{3}$; Celso Dornelas Fernandes ${ }^{4}$; Alfredo Raul Abot ${ }^{5}$

\section{RESUMO}

A fruticultura no Estado de Mato Grosso do Sul carece de informações sobre o potencial de produção de mudas. O objetivo deste trabalho foi avaliar a produção de mudas de mamoeiro, cultivar Sunrise Solo, em diferentes substratos industrializados e solo. O experimento foi realizado na Universidade Estadual do Mato Grosso do Sul (UEMS), campus Aquidauana, no período de 18/11/2008 a 05/01/2009. Foram utilizados três ambientes de cultivo protegido, três tamanhos de sacola de polietileno e seis substratos. Utilizou-se um delineamento inteiramente casualizado, em parcelas sub-subdivididas. Constatou-se que a sacola de 15,0 x 21,5 cm (1539,8 cm³) propicia as melhores mudas, e pelo índice de qualidade de Dikson todos os ambientes foram propícios à formação das mudas nesse recipiente. A vermiculita adubada com 14\% de composto orgânico é o melhor substrato na formação de mudas de mamoeiro e pelo índice de qualidade de Dikson esse substrato apresentou mudas com menor qualidade sob sombrite.

Palavras-chave: Carica papaya L., estufa, recipientes, sacolas de polietileno, telas de sombreamento.

\section{ABSTRACT}

\section{Papaya seedling formation in different substrates and protected environments}

The cultivation of fruits in the State of Mato Grosso do Sul, Brazil, lacks information on the potential of seedling production. The aim of this study was to evaluate the production of papaya cultivar Sunrise Solo, in industrialized substrates and soil. The experiment was carried out in the State University of Mato Grosso do Sul (UEMS), Aquidauana, from 18/11/2008 to 05/01/2009. Three protected cultivation environments, three sizes of polyethylene bags and six substrates were used in the treatments. The experimental design was a complete randomized in a split-plot scheme. The results showed that the 15.0 x $21.5 \mathrm{~cm}$ bag $\left(1539.8 \mathrm{~cm}^{3}\right)$ provided the best seedlings and the Dikson quality index showed that all environments were appropriate for seedling formation in this container. The vermiculite fertilized with $14 \%$ organic compost was the best substrate for the formation of papaya seedlings. The Dikson quality index showed that seedlings produced in this substrate had lower quality under plastic shade netting

Key words: Carica papaya L., containers, greenhouse, shade netting, polyethylene bags

\footnotetext{
Recebido para publicação em março de 2010 e aprovado em novembro de 2010

${ }^{1}$ Engenheiro Agrícola, Doutor, Unidade de Aquidauana, UEMS, Rodovia Aquidauana, Cera, Km 12, 79200-000, Aquidauana, MS, Brasil. mestrine@uems.br (autor para correspondência)

${ }^{2}$ Graduanda do curso de Agronomia, Unidade de Aquidauana, UEMS, Rodovia Aquidauana , Cera, Km 12, 79200-000, Aquidauana , MS, Brasil. vivi_maral99@hotmail.com ${ }^{3}$ Engenheiro Agrícola, Doutor, Faculdade de Engenharia Agrícola, Universidade Estadual de Campinas, Caixa Postal 6011, Barão Geraldo, 13083-970, Campinas,SP, Brasil. pamleal@feagri.unicamp.br

${ }^{4}$ Engenheiro-Agrônomo, Doutor, Embrapa Gado de Corte, Caixa Postal 154, 79002-970, Campo Grande, MS, Brasil. celsof@cnpgc.embrapa.br.

${ }^{5}$ Engenheiro-Agrônomo, Doutor, Unidade de Aquidauana, UEMS, Rodovia Aquidauana, Cera, Km 12, 79200-000, Aquidauana, MS, Brasil. arabot@uems.br
} 


\section{INTRODUÇÃO}

Dentre os vários fatores relacionados com a formação de mudas, o substrato exerce importância incontestável, devendo apresentar propriedades favoráveis ao desenvolvimento da planta, quais sejam aeração e porosidade adequadas, isenção de micro-organismos patogênicos e disponibilidade de todos os nutrientes necessários ao seu desenvolvimento (Minami, 2000; Mendonça et al., 2002).

Paulus \& Paulus (2007) destacam que a qualidade final de mudas relaciona-se diretamente à interação substrato x espécie. Mesmo quando oriundos de um único material, muitos substratos requerem suplementação mineral (Yamanishi et al., 2004; Corrêa et al., 2005; Nomura et al., 2008) ou orgânica (Canesin \& Corrêa, 2006) para atender as especificidades dessa interação.

Conforme Mendonça et al. (2006), substratos adubados com $10 \mathrm{~kg} \cdot \mathrm{m}^{-3}$ de superfosfato simples proporcionam qualidade a mudas de mamoeiro, enquanto que substratos com $40 \%$ de composto orgânico são eficientes no incremento da disponibilidade de minerais provenientes da decomposição da matéria orgânica à planta. Os mesmos autores observaram que a utilização conjunta de adubo e composto orgânico promoveu crescimento linear em altura, comprovando o efeito benéfico das adubações ao desenvolvimento das mudas.

Outro importante requisito na formação de mudas é o ambiente de cultivo (Segovia et al., 1997; Sousa et al., 1997). Mudas provenientes de ambientes protegidos, com maior porte e vigor, apresentam melhores resultados a campo (Cavalcante et al., 2002; Zanella et al., 2006), podendo garantir rápida formação do pomar, homogeneidade da cultura e precocidade da colheita (Franco \& Prado, 2008).

Os ambientes protegidos para produção vegetal são recobertos, em sua maioria, por filme de polietileno de baixa densidade (estufas agrícolas), contudo, telas de sombreamento, como as de monofilamentos (sombrite ${ }^{\circledR}$ ) e as termorrefletoras (aluminet ${ }^{\circledR}$ ) são amplamente usadas. Esses materiais podem ser utilizados isoladamente ou em conjunto, procurando proporcionar à planta melhores condições de desenvolvimento.

Este trabalho teve como objetivo avaliar a formação de mudas de mamoeiro em diferentes ambientes de cultivo empregando diferentes volumes de material industrializado e solo.

\section{MATERIAL E MÉTODOS}

O experimento, que avaliou o crescimento e qualidade de mudas de mamoeiro, cultivar Sunrise solo, produzidas em três ambientes de cultivo e com três volumes de substratos industrializados e solo, foi conduzido na área experimental da Universidade Estadual de Mato Grosso do Sul (UEMS), na Unidade Universitária de Aquidauana, entre os meses de novembro de 2008 e janeiro de 2009. Essa unidade se localiza a altitude de $174 \mathrm{~m}$, longitude de $-55,67^{\circ}$ e latitude de $-20,45^{\circ}$, região de interface entre Cerrado e Pantanal. O clima da região, de acordo com a classificação de Köppen, é Aw, definido como clima tropical úmido e com temperatura média anual de $29^{\circ} \mathrm{C}$.

As mudas ficaram acondicionadas em três ambientes protegidos: estufa agrícola (A1) em arco $(6,40 \mathrm{~m} x$ 18,00m x 4,00m) de estrutura em aço galvanizado, com abertura zenital na cumeeira, coberta com filme polietileno de 150 ìm, difusor de luz, possuindo tela termorrefletora de $50 \%$ sob o filme e fechamentos laterais e frontais com tela de monofilamento, malha para $50 \%$ de sombra; telado (A2), de estrutura em aço galvanizado (6,40m x 18,00m x 3,50 ), fechamento em $45^{\circ}$, com tela de monofilamento, malha com $50 \%$ de sombra (sombrite ${ }^{\circledR}$ ) e telado (A3) de estrutura em aço galvanizado (6,40m x 18,00m x 3,50), fechamento em $45^{\circ}$ com tela termorrefletora com $50 \%$ de sombra (aluminet ${ }^{\circledR}$ ).

Foram utilizadas sacolas de polietileno com diferentes tamanhos e volumes: T1 (7,5 cm x 11,5 cm, 205,9 cm $)$; T2 $\left(10,0 \mathrm{~cm}\right.$ x 16,5 cm, 525,2 $\left.\mathrm{cm}^{3}\right)$ e T3 $(15,0 \mathrm{~cm}$ x 21,5 cm, 1539,8 $\mathrm{cm}^{3}$ ), preenchidas com solo (S1) (Tabela 1); plantmax ${ }^{\circledR}(\mathrm{S} 2)$; vermiculita (S3); fibra de coco (S4); fibra de coco chips (S5) e composto orgânico Organosuper® (S6) (Tabela 1). Utilizou-se solo, classificado como Argissolo Vermelho-Amarelo (Embrapa, 2006), da camada de 10 a $20 \mathrm{~cm}$.

O experimento foi estabelecido utilizado o delineamento inteiramente casualizado, em esquema de parcelas subsubdivididas, ( 3 ambientes x 3 volumes x 6 substratos), com oito repetições (plantas), sendo as parcelas principais os ambientes de cultivo, as subparcelas as sacolas de polietileno e as sub-subparcelas os substratos.

Os substratos de S1 a S5 foram adubados com 14\% de composto orgânico (Organosuper ${ }^{\circledR}$ ), em volume, e doses de 2,5 kg de superfosfato simples, $0,3 \mathrm{~kg}$ de cloreto de potássio e 1,5 kg de calcário dolomítico por metro cúbico de substrato. Todos os substratos ficaram em repouso por dez dias antes da realização da semeadura, dentro dos ambientes, sendo irrigados com rega manual de manhã e de tarde para melhorar a mineralização da matéria orgânica presente no composto.

A semeadura ocorreu em 18/11/2008 e foram colocadas duas sementes por sacola. No dia 15/12/2008, foi realizado o desbaste, deixando uma planta por sacola. Aos 48 dias após a semeadura (DAS), foram medidas as alturas das plantas (AP) e as biomassas secas das partes aéreas (MSA) e dos sistemas radiculares (MSR). Somaram-se as MSA e MSR para obtenção de biomassa seca total (MST). Avaliou-se, também, o diâmetro do colo (DC) das plantas. Foram determinadas as relações altura/diâ- 
metro do colo (RAD) e o índice de qualidade de Dickson (IQD), determinado por: IQD = MST / (Relação altura/ diâmetro + relação biomassa seca aérea / radicular) (Dickson et al., 1960).

Em cada ambiente de cultivo foram determinadas as temperaturas de bulbo seco e de bulbo úmido às $9,12 \mathrm{e}$ 15 horas, no período de 18 de novembro a 05 de janeiro de 2009. Posteriormente, obteve-se a umidade relativa com auxílio do software Psychrometric Function Demo (Tabela 1).

Os dados foram submetidos à análise de variância e as médias comparadas pelo teste de Tukey, a 5\% de probabilidade, utilizando o software Estat (1994).

\section{RESULTADOS E DISCUSSÃO}

Na interação ambiente de cultivo e tamanho da sacola (Tabela 2), o desenvolvimento das mudas foi sempre superior na sacola de polietileno de maior tamanho e volume $(15,0$ x 21,5 cm), atingindo maior altura $(26,2 \mathrm{~cm})$ e maior biomassa seca total $(1,41 \mathrm{~g})$ no telado com tela de monofilamento de $50 \%$ de sombreamento. Na interação ambiente de cultivo e substrato, porém, a maior altura foi obtida no aluminete $(29,1 \mathrm{~cm})$ e, na interação tamanho da sacola e substrato foi de $37,6 \mathrm{~cm}$ na sacola de 15,0x21,5 cm (Tabela 3), sempre no substrato vermiculita.

De acordo com o relato de Nogueira Filho \& Castro (2003), que afirmam que mudas de mamoeiro devem ter entre 15 e $25 \mathrm{~cm}$ de altura, neste experimento, somente a sacola de 15,0x21,5 cm proporcionou plantas aptas para serem plantadas no campo. Porém, ao se considerar a interação com o substrato, observa-se que a vermiculita (S3) e o composto orgânico (S6) produziram mudas aptas para plantio no campo (Tabela 4). Se a sacola com 10,0cm $\mathrm{x} 16,5 \mathrm{~cm}, 525,2 \mathrm{~cm}^{3}$, de volume inferior ao de T3, proporcionasse mudas de boa qualidade para transplante, haveria economia de substrato e de espaço no ambiente de cultivo, contudo, verificou-se que com 48 dias de cultivo nes- se recipiente as plantas não atingiram a altura desejada, necessitando, provavelmente de maior tempo. Entretanto, maior tempo das mudas no ambiente de cultivo implicaria necessidade de nutrição extra em decorrência da provável escassez de nutrientes dos substratos, ou seja, adubação suplementar, conforme observado por Canesin \& Corrêa (2006), e, em vista disso, aumentariam os custos de produção de mudas.

No recipiente com maior tamanho e volume (T3), as plantas desenvolveram-se melhor no viveiro com tela de monofilamento de $50 \%$ de sombra (A2), apresentando maior altura e maior acúmulo de biomassa foliar e total. Entretanto, pelo índice de qualidade de Dickson, todos os ambientes de cultivo produziram mudas de qualidade quando se empregou esse tamanho de sacola (Tabela 2). Esses resultados são semelhantes aos obtidos por Costa et al. (2009) que observaram melhor crescimento de mudas de maracujá amarelo nesse tipo de recipiente e ambiente.

O menor desenvolvimento das plantas, observado na estufa plástica (A1), em relação ao telado com sombrite ${ }^{\circledR}$, tanto no composto orgânico Organosuper® (Tabelas 3 e 4), como na sacola de maior volume (Tabela 2), pode estar relacionado com a maior evapotranspiração que esse ambiente proporciona. Araújo et al. (2006) obtiveram melhores mudas de mamoeiro em ambiente a céu aberto em comparação com a estufa plástica e telado. Mendonça et al. (2008), com tamarindeiro (Tamarindus indica L.) e Carvalho Filho et al. (2003), com jatobá (Hymenaea courbaril L.) obtiveram melhores mudas em ambiente a céu aberto em comparação com o telado com $50 \%$ de sombreamento. No entanto, em ambiente telado com 50\% de sombreamento, mudas de Angelim (Andira fraxinifolia Benth.) apresentaram maior altura no substrato solo, areia, esterco bovino 1:2:1 (Carvalho Filho et al. 2004), e em Canafístula (Cassia grandis L.) foi verificado maior velocidade de crescimento (Carvalho Filho et al., 2002).

Tabela 1. Análise química do solo (S1) e do composto orgânico (S6) e temperaturas ( ${ }^{\circ} \mathrm{C}$ ) e umidade relativa média (\%) nos horários das 09, 12 e 15h para cada ambiente (A) de cultivo

\begin{tabular}{|c|c|c|c|c|c|c|c|c|c|}
\hline$*$ & $\mathbf{p H}$ & M.O. & $\mathbf{K}$ & Ca & Mg & $\mathbf{H}+\mathbf{A l}$ & SB & $\mathbf{T}$ & $\mathbf{V}$ \\
\hline & & $\%$ & 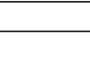 & 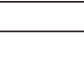 & $-\mathrm{cn}$ & $\mathrm{m}^{-3}$ & 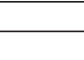 & 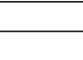 & $\%$ \\
\hline S1 & 5,4 & 1,4 & 0,4 & 0,9 & 0,8 & 3,3 & 2,1 & 5,4 & 38,9 \\
\hline S6 & 6,5 & 5,0 & 2,6 & 15,7 & 0,7 & 2,7 & 19,0 & 21,7 & 87,6 \\
\hline \multirow[t]{2}{*}{$* *$} & TBS & TBU & TBS & TBU & TBS & TBU & & UR & \\
\hline & \multicolumn{2}{|c|}{09 H } & \multicolumn{2}{|c|}{$12 \mathrm{H}$} & \multicolumn{2}{|c|}{$15 \mathrm{H}$} & $09 \mathrm{H}$ & $12 \mathrm{H}$ & $15 \mathrm{H}$ \\
\hline A1 & 30,1 & 24,2 & 33,6 & 26,0 & 36,8 & 26,7 & 63,3 & 56,5 & 47,9 \\
\hline A2 & 29,6 & 24,3 & 33,7 & 25,9 & 36,1 & 26,7 & 66,7 & 55,4 & 50,9 \\
\hline A3 & 30,2 & 25,1 & 33,9 & 26,7 & 36,9 & 27,7 & 67,7 & 59,0 & 52,1 \\
\hline
\end{tabular}

* Fonte: Laboratório de análises do solo da agência estadual de defesa sanitária animal e vegetal de MS.

** $\mathrm{TBS}=$ temperatura de bulbo seco $\left({ }^{\circ} \mathrm{C}\right)$; TBU = temperatura de bulbo úmido $\left({ }^{\circ} \mathrm{C}\right)$; UR = umidade relativa $(\%)$. 
Mendonça et al. (2005) obtiveram melhores mudas de mamoeiro 'Formosa', trabalhando em casa de vegetação climatizada do que em telado coberto por sombrite com 50 \% de sombreamento. Níveis de sombreamento de 0, 30 e 50 \% não influenciaram na altura e diâmetro do colo de Eriotheca pubescens Mart. \& Zucc. (Carrijo et al., 2009), porém em mudas de turco (Parkinsonia aculeata L.), o nível 0 \% de sombreamento promoveu melhores mudas que o telado de $75 \%$ de acordo com Farias Júnior et al. (2007).

Na estufa plástica, a umidade relativa do ar diminui de acordo com o aquecimento do ar (Costa et al., 2004), havendo também redução no processo convectivo devido à cobertura (Cunha \& Escobedo, 2003) e nesse processo pode ocorrer maior evapotranspiração. Por essa razão, mesmo possuindo abertura zenital e tela termorrefletora, nesse ambiente as plantas apresentaram menor desenvolvimento.

No telado com sombrite a 50\% de sombreamento (A2), o substrato com $100 \%$ de composto orgânico produziu plantas com alturas semelhantes às obtidas com a vermiculita, porém na estufa (A1) e no viveiro com aluminete (A3), o valor dessa característica foi inferior, provavelmente, por causa do estoque menor de nutrientes (Tabela 3).

Para produção de mudas de hortaliças, vários autores recomendam a utilização do substrato plantmax ${ }^{\circledR}$. Para a formação de mudas do mamoeiro, no entanto, esse produ- to não alcançou resultado satisfatório o que está de acordo com Mendonça et al. (2003), que, ao trabalharem esse material puro ou em mistura com carvão vegetal, solo e areia obtiveram resultado inferior ao alcançado com mistura de esterco de curral, carvão vegetal, solo e areia na formação de mudas do mamoeiro.

Negreiros et al. (2005), também, concluíram que o plantmax ${ }^{\circledR}$ puro ou em mistura com solo, areia e vermiculita promoveram menor desenvolvimento de mudas de mamoeiro comparado com o substrato, contendo esterco de curral, solo, areia e vermiculita. Na formação de mudas de mamão ‘Formosa', Mendonça et al. (2004) verificaram que a mistura de plantmax ${ }^{\circledR}$, areia e solo promoveram menor crescimento que a mistura esterco de curral, casca de café, carvão vegetal, areia e solo, ambos adubados com osmocote ${ }^{\circledR}$.

Não houve interação entre ambiente e tamanho da sacola para o diâmetro do colo (DC). Nas interações "ambiente e substrato", "tamanho da sacola e substrato", verificou-se que os maiores diâmetros de colo foram obtidos na vermiculita (S3) e no composto orgânico (S6) semelhantemente à altura de planta, observando-se que plantas mais altas estavam com maior diâmetro, não caracterizando estiolamento (Tabela 3 ). No substrato que promoveu maior crescimento (S3), o menor diâmetro de colo foi verificado no telado com sombrite $50 \%$ (Tabela 3), podendo induzir à interpretação de um possível estiolamento, porém quando se observa a relação altura/

Tabela 2. Interações entre ambientes e tamanho das sacolas (A x T) para altura de planta (AP), biomassa seca da parte aérea (MSA), biomassa seca total (MST), relação altura de planta e diâmetro do colo (RAD) e índice de qualidade de Dickson (IQD)

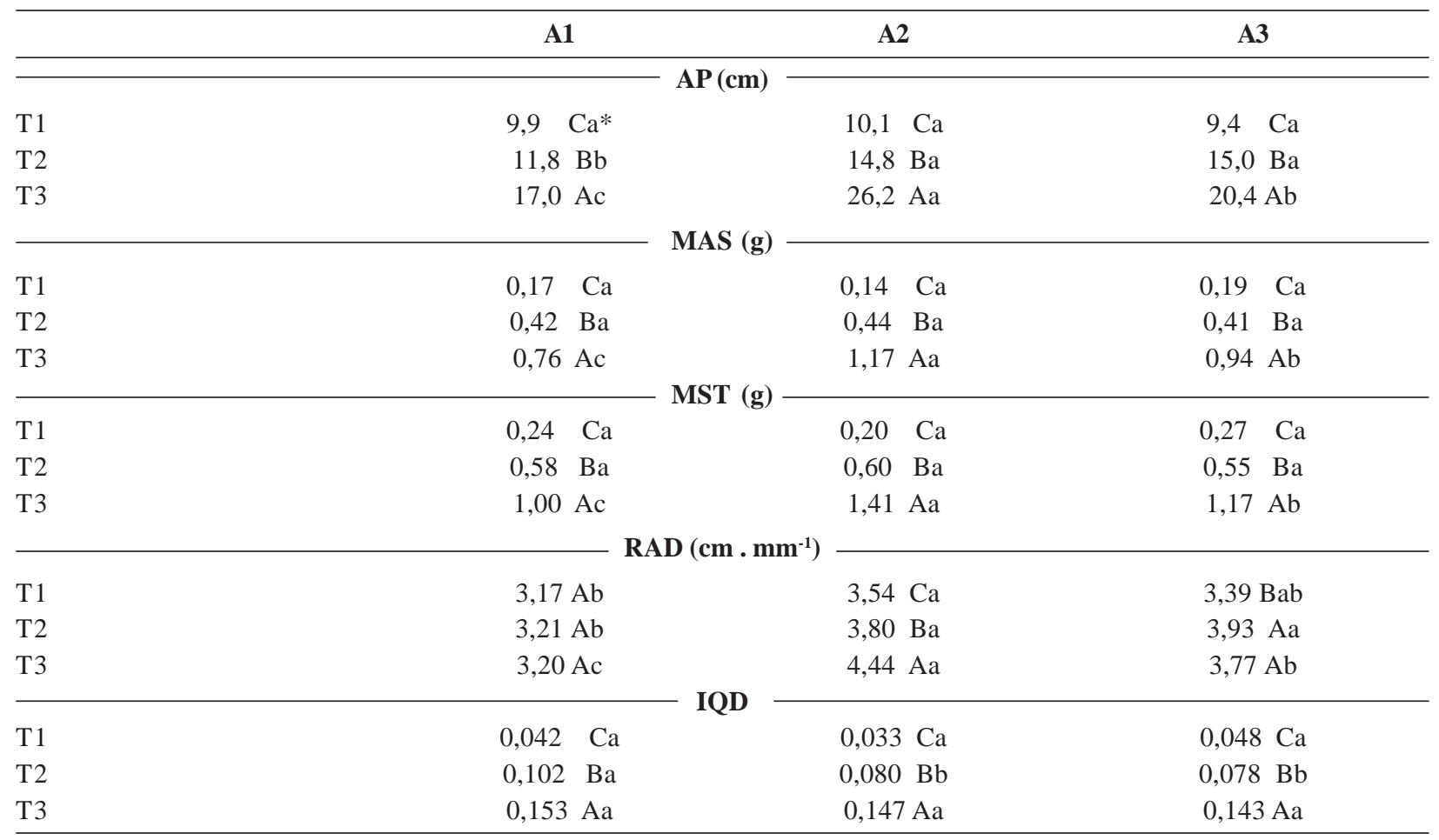

*Letras iguais maiúsculas nas colunas e minúsculas nas linhas não diferem entre si (Tukey a 5\% de probabilidade).

Rev. Ceres, Viçosa, v. 57, n.5, p. 679-685, set/out, 2010 
diâmetro (RAD) nesse ambiente o menor valor foi encontrado no substrato S1 assim como na estufa agrícola e nos recipientes com maior volume (Tabela 4).

O diâmetro do colo, associado à altura da planta, revela se houve estiolamento ou não, pois segundo Cruz et al. (2006) a RAD exprime um equilíbrio no crescimento da muda, relacionando duas importantes características morfológicas em um único índice. Esta observação parte do princípio que plantas altas com diâmetro do colo esbelto podem ocorrer pela falta de luminosidade e possível estiolamento. Aos 48 DAS, verificou-se que essa relação (altura/diâmetro) foi similar em todos os tratamentos no ambiente com aluminete, indicando que as mudas não estiolaram nesse ambiente.

A interpretação isolada da variável RAD nas plantas do substrato S6 induziria a afirmar que, no telado, houve estiolamento; porém, quando se observam a massa de matéria seca total (MST) e a massa de matéria seca da raiz (MSR), nota-se que o maior acúmulo de biomassa aérea foi obtido nesse ambiente, assim como o índice de quali- dade de Dickson (Tabela 4). Porém, Araújo et al. (2006) observaram, aos 60 DAS, em viveiro telado com $50 \%$ de sombreamento, crescimento excessivo e estiolamento em mudas de mamoeiro.

Pelo índice de qualidade de Dickson (IQD), para todos os substratos, o recipiente de maior tamanho e volume produziu melhores mudas, estando de acordo com os resultados obtidos por Mendonça et al. (2003) em mudas de mamoeiro, Ribeiro et al. (2005) e Costa et al. (2009) em mudas de maracujazeiro amarelo, Carvalho Filho et al. (2003) em mudas de jatobá (Hymenaea courbaril L.), Freitas et al. (2006) em miniestacas de eucalipto (Eucalyptus grandis Hill ex Maiden e E. saligna Smith), Viana et al. (2008) em mudas de pata-de-vaca (Bauhinia forficata Link), Farias Júnior et al. (2007) em mudas de turco (Parkinsonia aculeata L.) e Vallone et al. (2009) em mudas de cafeeiro (Coffea arabica L.). Os resultados obtidos evidenciam que o tamanho do recipiente influencia o crescimento, o desenvolvimento e a qualidade inicial das mudas.

Tabela 3. Interações entre ambientes e substratos (A x S), tamanho das sacolas e substratos ( $\mathrm{T} \times \mathrm{S}$ ) para a altura de planta (AP), diâmetro do colo (DC), biomassa seca da parte aérea (MSA), e biomassa seca radicular (MSR), aos 48 DAS

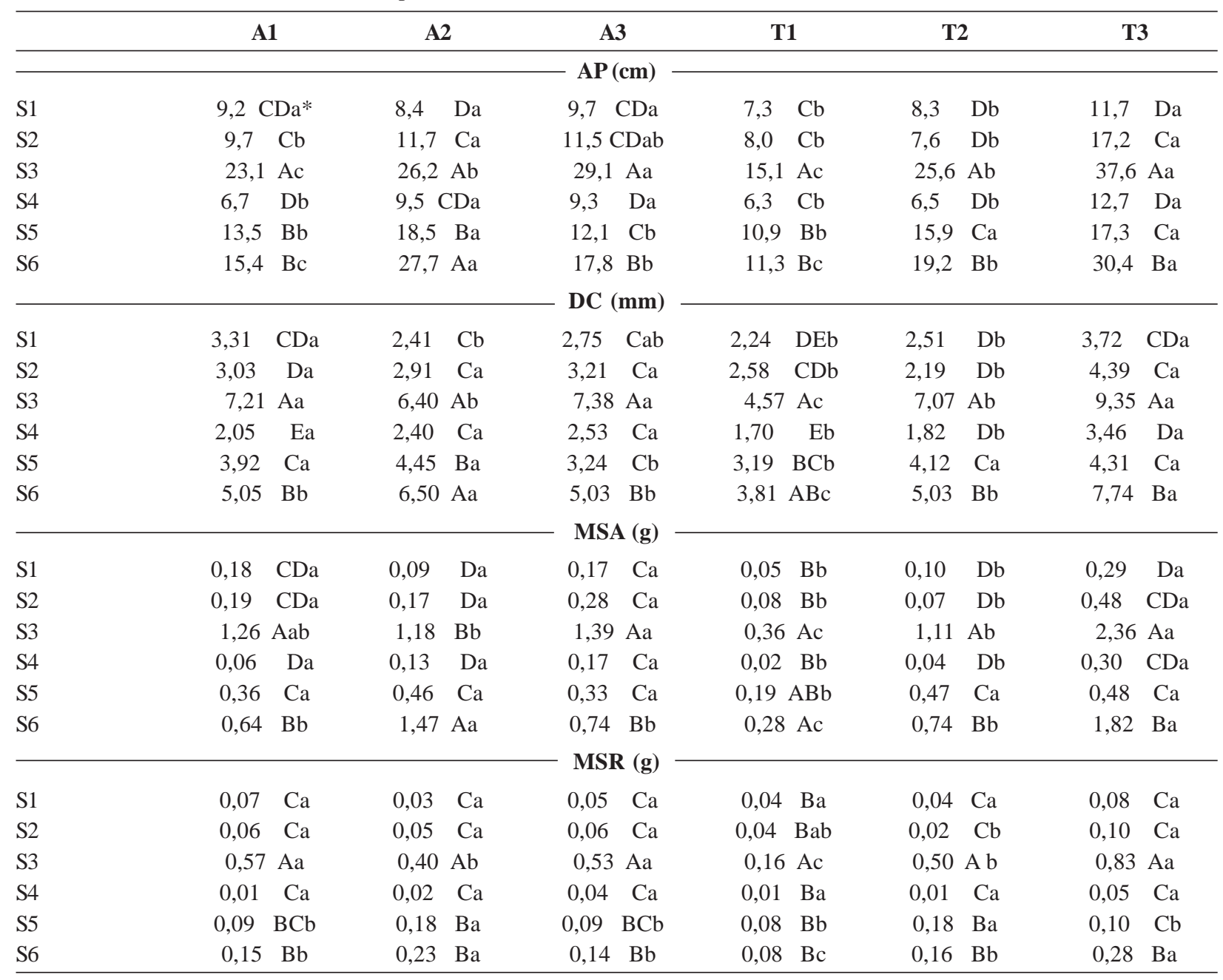

*Letras iguais maiúsculas nas colunas e minúsculas nas linhas não diferem entre si (Tukey a 5\% de probabilidade). 
Tabela 4 - Interações entre ambientes e substratos (A x S), recipientes e substratos (T x S) para a biomassa seca total (MST), relação altura de planta e diâmetro do colo (RAD) e índice de qualidade de Dickson (IQD), aos 48 DAS

\begin{tabular}{|c|c|c|c|c|c|c|}
\hline & A1 & A2 & A3 & T1 & $\mathbf{T} 2$ & T3 \\
\hline & & & — MST (g) & & & \\
\hline S1 & 0,25 CDa* & 0,13 Ca & $0,22 \mathrm{CDa}$ & 0,09 CDb & $0,14 \mathrm{Db}$ & 0,37 Da \\
\hline S2 & $0,25 \mathrm{CDa}$ & $0,22 \mathrm{Ca}$ & 0,34 CDa & 0,13 CDb & 0,10 Db & 0,58 Ca \\
\hline S3 & 1,83 Аа & 1,58 Ab & 1,92 Аа & $0,52 \mathrm{Ac}$ & 1,62 Ab & 3,19 Аа \\
\hline S4 & 0,07 Da & $0,16 \mathrm{Ca}$ & $0,21 \mathrm{Da}$ & $0,03 \mathrm{Db}$ & 0,05 Db & $0,36 \mathrm{Da}$ \\
\hline S5 & $0,45 \mathrm{Cb}$ & 0,64 Ba & $0,42 \mathrm{Cb}$ & $0,27 \mathrm{BCb}$ & 0,65 Ca & $0,59 \mathrm{Ca}$ \\
\hline \multirow[t]{2}{*}{ S6 } & 0,79 Bb & 1,70 Аа & 0,87 Bb & $0,36 \mathrm{ABc}$ & 0,90 Bb & 2,10 Ba \\
\hline & & & RAD (cm mn & & & \\
\hline S1 & 2,85 Cb & 3,54 Ca & 3,57 Aa & 3,36 Ba & 3,30 Ca & 3,30 Ca \\
\hline S2 & $3,30 \mathrm{ABb}$ & 3,82 BCa & 3,56 Aab & 3,18 ВСс & 3,55 BCb & 3,95 ABa \\
\hline S3 & $3,22 \mathrm{ABb}$ & 4,05 ABa & 3,84 Аа & $3,40 \mathrm{Bb}$ & 3,63 BCb & 4,08 Aa \\
\hline S4 & 3,33 ABb & 3,92 ABa & 3,84 Aa & 3,78 Аа & 3,59 BCa & 3,72 Ba \\
\hline S5 & 3,44 Ab & 4,16 Аа & $3,71 \mathrm{Ab}$ & $3,50 \mathrm{ABb}$ & 3,86 ABa & 3,94 ABa \\
\hline S6 & 3,04 BCc & 4,07 ABa & 3,67 Ab & 2,97 Cb & 3,98 Аа & $3,84 \mathrm{ABa}$ \\
\hline S1 & 0,045 Ca & 0,020 Da & 0,032 CDa & 0,020 CDb & 0,023 Cb & $0,054 \mathrm{Ca}$ \\
\hline S2 & 0,038 CDa & 0,028 Da & 0,040 CDa & 0,025BCDb & 0,014 Cb & 0,067 Ca \\
\hline S3 & 0,334 Аа & 0,220 Ac & $0,282 \mathrm{Ab}$ & 0,095 Aс & $0,280 \mathrm{Ab}$ & $0,461 \mathrm{Aa}$ \\
\hline S4 & 0,008 Da & 0,015 Da & 0,026 Da & $0,006 \mathrm{Db}$ & $0,007 \mathrm{Cb}$ & 0,036 Ca \\
\hline S5 & $0,057 \mathrm{Cb}$ & 0,085 Ca & 0,058 Cab & $0,044 \mathrm{BCb}$ & 0,091 Ba & 0,065 Cb \\
\hline S6 & 0,110 Bb & 0,153 Ва & 0,101 Bb & 0,056 Bc & 0,107 Bb & 0,201 Ва \\
\hline
\end{tabular}

*Letras iguais maiúsculas nas colunas e minúsculas nas linhas não diferem entre si (Tukey a 5\% de probabilidade).

As diferentes características avaliadas, especialmente o IDQ, indicam que tanto nos diferentes ambientes quanto nos diferentes tamanhos de sacola, a vermiculita (S3) propiciou as melhores mudas (Tabelas 3 e 4). Porém, pelo IDQ verifica-se que esse substrato apresentou mudas de menor qualidade no telado, possivelmente pela menor produção de MST proveniente da menor MSR e menor diâmetro do colo (Tabela 4). A produção das melhores mudas, na vermiculita, pode ser explicada pelas propriedades de retenção de água que esse material possui e pela sua capacidade de aeração (Costa et al., 2009).

No substrato S6 (100\% de composto orgânico), surgiram no sistema radicular e no coleto das mudas pequenas galhas, com formato irregular, caracterizadas pela formação de pústulas com consistência semelhante a isopor finamente granulado e que, quando observadas sob estereomicroscópio com 10x de aumento, apresentavam lesões superficiais no tecido cortical. Amostras das plantas sintomáticas foram analisadas no laboratório de Fitopalogia da Embrapa Gado de Corte, em Campo Grande, MS, não sendo constatada a presença de agentes bióticos. Provavelmente, tais sintomas foram provenientes do maior, aquecimento do substrato por causa da sua coloração escura, que absorve mais calor, além da decomposição da matéria orgânica. No campo os sintomas não evoluíram e as plantas desenvolveram-se normalmente.

\section{CONCLUSÕES}

A sacola de 15,0 x 21,5 cm $\left(1539,8 \mathrm{~cm}^{3}\right)$ propicia mudas de melhor qualidade. Pelo índice de qualidade de Dikson, para esse tamanho de sacola, todos os ambientes foram propícios à formação das mudas.

A vermiculita adubada com 14\% de composto orgânico é o melhor substrato na formação de mudas de mamoeiro. As mudas produzidas sob sombrite apresentam a menor qualidade, avaliada pelo índice de qualidade de Dikson, para esse substrato.

\section{REFERÊNCIAS}

Araújo JG, Araújo Júnior MM, Menezes RHN, Martins MR, Lemos RNS \& Cerqueira MC (2006) Efeito do recipiente e ambiente de cultivo sobre o desenvolvimento de mudas de mamoeiro cv. sunrise solo. Revista Brasileira de Fruticultura, 28:526-529.

Canesin RCFS \& Corrêa LS (2006) Uso de esterco associado à adubação mineral na produção de mudas de mamoeiro (Carica papaya L.). Revista Brasileira de Fruticultura, 28:481-486.

Carrijo C, Martins RCC, Martins IS, Landahl DT, Matos JMM \& Nakano TYR (2009) Estabelecimento de Eriotheca pubescens (Bombacaceae) por meio de semeadura direta e de mudas em cascalheira. Cerne, 15:365-370.

Carvalho Filho JLS, Arrigoni-Blank MF, Blank AF, Santos Neto AL \& Amâncio VF (2002) Produção de mudas de Cassia grandis L. em diferentes, recipientes e misturas de substratos. Revista Ceres, 49:341-352. 
Carvalho Filho JLS, Arrigoni-Blank MF, Blank AF \& Rangel MAS (2003) Produção de mudas de jatobá (Hymenaea courbaril L.) em diferentes ambientes, recipientes e composições de substratos. Cerne, 9:111-121.

Carvalho Filho JLS, Arrigoni-Blank MF \& Blank AF (2004) Produção de mudas de angelim (Andira fraxinifolia Benth.) em diferentes ambientes, recipientes e composições de substratos. Revista Ciência Agronômica, 35:61-67.

Cavalcante LF, Santos JB, Santos CJO, Feitosa Filho JC, Lima EM \& Cavalcante IHL (2002) Germinação de sementes e crescimento inicial de maracujazeiros irrigados com água salina em diferentes volumes de substrato. Revista Brasileira de Fruticultura, 24:748-751.

Corrêa MCM, Natale W, Prado RM, Oliveira IVM \& Almeida EV (2005) Adubação com zinco na formação de mudas de mamoeiro. Caatinga, 18:245-250.

Costa E, Leal PAM \& Carmo Junior RR (2004) Modelo de simulação da temperatura e umidade relativa do ar no interior da estufa plástica. Revista Engenharia Agrícola, 24:57-67.

Costa E, Rodrigues ET, Alves VB, Santos LCR \& Vieira LCR (2009) Efeitos da ambiência, recipientes e substratos no desenvolvimento de mudas de maracujazeiro-amarelo em Aquidauana MS. Revista Brasileira de Fruticultura, 31:236-244.

Cruz CAF, Paiva HN \& Guerrero CRA (2006) Efeito da adubação nitrogenada na produção de mudas de sete-cascas (Samanea inopinata (Harms) Ducke). Revista Árvore, 30:537-546.

Cunha AR \& Escobedo JF (2003) Alterações micrometeorológicas causadas pela estufa plástica e seus efeitos no crescimento e produção da cultura de pimentão. Revista Brasileira de Agrometeorologia, 11:15-27.

Dickson A, Leaf AL \& Hosner JF (1960) Quality appraisal of white spruce and white pine seedling stock in nurseries. Forestry Chronicle, 36:10-13.

EMPRESA BRASILEIRA DE PESQUISA AGROPECUÁRIA - Centro Nacional de Pesquisa de Solos (2006). Sistema brasileiro de classificação de solos. Brasília. EMBRAPA, 305p.

Estat (1994) Sistema para análises estatísticas (v. 2.0). Jaboticabal: Departamento de Ciências Exatas, FCAV-UNESP.

Farias Junior JA, Cunha MCL, Farias SGG \& Menezes Junior JC (2007) Crescimento inicial de mudas de turco sob diferentes tipos de recipientes e níveis de luminosidade. Revista Brasileira de Ciências Agrárias, 2:228-232.

Franco CF \& Prado RM (2008) Nutrição de micronutrientes em mudas de goiabeira em resposta ao uso de soluções nutritivas. Acta Scientiarum. Agronomy, 30:403-408.

Freitas TAS, Barroso DG, Carneiro JGA, Penchel RM \& Figueiredo FAMMA (2006) Mudas de eucalipto produzidas a partir de miniestacas em diferentes recipientes e substratos. Revista Árvore, 30:519-528.

Mendonça V, Araújo Neto SE, Ramos JD, Pio R \& Gontijo TCA (2003) Diferentes substratos e recipientes na formação de mudas de mamoeiro'sunrise solo'. Revista Brasileira de Fruticultura, 25:127-130.

Mendonça V, Ramos JD, Araújo Neto SE, Pio R, Gontijo TCA \& Junqueira KP (2002) Substratos e quebra de dormência na formação do porta-enxerto de gravioleira cv. RBR. Revista Ceres, 49:657-668.
Mendonça V, Ramos JD, Dantas DJ, Martins PCC, Gontijo TCA \& Pio R (2004) Efeito de doses de Osmocote e dois tipos de substratos no crescimento de mudas do mamoeiro 'Formosa'. Revista Ceres, 51:467-476.

Mendonça V, Ramos JD, Carrijo EP, Pio R, Dantas DJ \& Gontijo TCA (2005) Diferentes ambientes e substratos na formação de mudas de mamoeiro 'Formosa'. Revista Científica Rural, 10:1824.

Mendonça V, Abreu NAA, Gurgel RLS, Ferreira EA, Orbes MY \& Tosta MS (2006) Crescimento de mudas de mamoeiro "formosa” em substratos com a utilização de composto orgânico e superfosfato simples. Ciência e Agrotecnologia, 30:861-868.

Mendonça V, Arruda NAA, Souza HA, Teixeira GA, Hafle OM \& Ramos JD (2008) Diferentes ambientes e osmocote ${ }^{\circledR}$ na produção de mudas de tamarindeiro (Tamarindus indica). Ciência e Agrotecnologia, 32:391-397.

Minami K (2000) A pesquisa em substrato no Brasil. In: KÄMPF NA, Fermino MH (Eds) Substratos para plantas: a base da produção vegetal em recipientes. Porto Alegre, Gênesis. p. 23-42.

Negreiros JRS, Braga LR, Álvares VS \& Bruckner CH (2005) Diferentes substratos na formação de mudas de mamoeiro do grupo solo. Revista Brasileira de Agrociência, 11:101-103.

Nogueira Filho GC \& Castro AM (2003) Recomendações técnicas para o cultivo do mamoeiro em Roraima. Boa Vista, Embrapa Roraima. 10p. (Circular Técnica 4).

Nomura ES, Lima JD, Garcia VA \& Rodrigues DS (2008) Crescimento de mudas micropropagadas da bananeira cv. Nanicão, em diferentes substratos e fontes de fertilizantes. Acta Scientiarum. Agronomy, 30:359-363.

Paulus D \& Paulus E (2007) Efeito de substratos agrícolas na produção de mudas de hortelã propagadas por estaquia. Horticultura Brasileira, 23:594-597.

Ribeiro MCC, Morais MJA, Sousa AH, Linhares PCF \& Barros Junior AP (2005) Produção de mudas de maracujá-amarelo com diferentes substratos e recipientes. Caatinga, 18:155-158.

Segovia JFO, Andriolo JL, Buriol GA \& Schneider FM (1997) Comparação do crescimento e desenvolvimento da alface (Lactuca sativa L.) no interior e no exterior de estufas de polietileno em Santa Maria, RS. Ciência Rural, 27:37-41.

Sousa JA, Ledo FJS \& Silva MR (1997) Produção de mudas de hortaliças em recipientes. Rio Branco, Embrapa Acre. 20p. (Circular Técnica 19).

Vallone HS, Guimarães RJ, Mendes ANG, Souza CAS, Dias FP \& Carvalho AM (2009) Recipientes e substratos na produção de mudas e no desenvolvimento inicial de cafeeiros após o plantio. Ciência e Agrotecnologia, 33:1327-1335.

Viana JS, Goncalves EP, Andrade LA, Oliveira LSB \& Silva EO (2008) Crescimento de mudas de Bauhinia forficata Link. em diferentes tamanhos de recipientes. Floresta, 38:663-671.

Yamanishi OK, Fagundes GR, Machado Filho JÁ \& Valone GV (2004) Efeito de diferentes substratos e duas formas de adubação na produção de mudas de mamoeiro. Revista Brasileira de Fruticultura, 26:276-279.

Zanella F, Soncela R \& Lima ALS (2006) Formação de mudas de maracujazeiro "amarelo" sob níveis de sombreamento em JiParaná/RO. Ciência e Agrotecnologia, 30:880-884. 